\title{
Efeito da temperatura de queima nas propriedades e microestrutura de cerâmica vermelha contendo chamote
}

\section{(Effect of the firing temperature on the properties and microstructure of red ceramic incorporated with grog)}

\author{
C.M. F. Vieira, S. S. Teixeira, S. N. Monteiro \\ Universidade Estadual do Norte Fluminense Darcy Ribeiro - UENF \\ Laboratório de Materiais Avançados - LAMAV \\ Av. Alberto Lamego, 2000, Campos dos Goytacazes, 28013-602 \\ vieira@uenf.br
}

\begin{abstract}
Resumo
Este trabalho tem por objetivo avaliar o efeito da temperatura de queima nas propriedades de uma cerâmica constituída por argila caulinítica e incorporada com até $20 \%$ em peso de chamote. Foram preparados corpos de prova cilíndricos por prensagem uniaxial a $20 \mathrm{MPa}$ para queima em forno de laboratório de 500 a $1100{ }^{\circ} \mathrm{C}$. As propriedades avaliadas foram densidade aparente, retração diametral, absorção de água e resistência mecânica. A microestrutura das cerâmicas foi avaliada por microscopia eletrônica de varredura e porosimetria de mercúrio. Os resultados indicaram que não houve variação significativa nas propriedades avaliadas entre 500 e $900{ }^{\circ} \mathrm{C}$. A partir daí, ocorreu uma redução brusca da porosidade que ocasionou um decréscimo da absorção de água e melhoria da resistência mecânica. A incorporação de 5\% de chamote praticamente não alterou as propriedades da cerâmica. Entretanto, foi observado que a adição de maiores quantidades de chamote reduziu a resistência mecânica de queima da cerâmica. Palavras-chave: Cerâmica vermelha, chamote, microestrutura, propriedades, rejeito, temperatura.
\end{abstract}

\begin{abstract}
This work has the objective of evaluating the effect of the firing temperature on the properties and microstructure of a kaolinitic clay incorporated with up to $20 \mathrm{wt}$ \% of grog. Cylindrical specimens uniaxially pressed under $20 \mathrm{MPa}$ were prepared and fired at temperatures ranging from 500 to $1100^{\circ} \mathrm{C}$ in a laboratory furnace. The properties evaluated were bulk density, diametral shrinkage, water absorption and mechanical strength. The microstructure of the ceramics was evaluated by scanning electron microscopy and mercury porosimetry. The results showed that no significant changes occurred in the evaluated properties of the compositions upon firing between 500 and $900^{\circ} \mathrm{C}$. For higher firing temperatures, an abrupt decrease in the porosity resulted in a decrease in water absorption and an increase in mechanical strength. The incorporation of $5 \mathrm{wt} \%$ of grog practically did not alter the properties of the ceramic. However, it was observed that higher amounts of grog decreased the fired mechanical strength of the clayey ceramic. Keywords: red ceramic, grog, microstructure, properties, waste, temperature.
\end{abstract}

\section{INTRODUÇÃO}

Peças defeituosas provenientes da etapa de queima da cerâmica vermelha podem eventualmente retornar ao processo, após trituração, gerando um resíduo cerâmico conhecido como chamote [1-5]. A vantagem principal da adição do chamote é facilitar a etapa de secagem. A morfologia e o tamanho das partículas do chamote promovem um aumento da permeabilidade da peça verde, facilitando a eliminação da água de conformação [6]. O chamote pode também melhorar a trabalhabilidade de massas cerâmicas eventualmente muito plásticas e conferir efeitos estéticos desejados na superfície dos produtos. Entretanto, o chamote é geralmente prejudicial à resistência mecânica das peças
[2], pois suas partículas inertes dificilmente aderem à matriz tornando-se pontos de concentração de tensão. Por outro lado, caso o chamote seja queimado uma segunda vez, acima de sua temperatura de processamento inicial, as reações e as transformações de sinterização que venham a ocorrer podem contribuir para minimizar ou até mesmo eliminar o efeito deletério na resistência mecânica. Em trabalho reportado na literatura [7] realizou-se a caracterização de um chamote obtido de blocos de vedação produzidos no município de Campos dos Goytacazes, Estado do Rio de Janeiro. Constatou-se que esse chamote é constituído por cerca de $5 \%$ em peso de partículas lamelares individualizadas extremamente pequenas, $<2 \mu \mathrm{m}$, e por agregados de partículas com porosidade intragranular, predominantes na 
faixa de 60-200 $\mu \mathrm{m}$. A presença de caulinita é um indicativo de que as temperaturas utilizadas para a fabricação dos blocos de vedação que originaram o chamote foram inferiores a $600{ }^{\circ} \mathrm{C}$ Em outros trabalhos [8,9] este mesmo chamote foi adicionado em até $20 \%$ em peso a uma argila para queima industrial a $970{ }^{\circ} \mathrm{C}$. Esta temperatura é típica da produção de telhas cerâmicas em Campos dos Goytacazes. Os resultados indicaram que o incremento da incorporação de chamote promoveu uma redução da retração linear de secagem da argila devido à diminuição de água de conformação. Nas propriedades de queima foi observado que a incorporação de chamote praticamente não alterou a absorção de água e a resistência mecânica das peças. Este resultado foi atribuído às reações de sinterização que ocorreram no chamote durante a segunda queima sob temperaturas acima de $600{ }^{\circ} \mathrm{C}$.

Tendo em vista o efeito térmico sobre o chamote, o objetivo deste trabalho foi investigar a influência da temperatura de queima, entre 500 e $1100{ }^{\circ} \mathrm{C}$, nas propriedades de uma cerâmica à base de argila caulinítica de Campos dos Goytacazes com adição de chamote.

\section{PROCEDIMENTO EXPERIMENTAL}

Para a realização deste trabalho foram utilizados chamote e argila, ambos provenientes do município de Campos dos Goytacazes, RJ. O chamote foi obtido da trituração e peneiramento em malha de abertura de $840 \mu \mathrm{m}$ (20 mesh), a partir de blocos de vedação queimados em temperaturas ao redor de $500-600{ }^{\circ} \mathrm{C}$. A Fig. 1 apresenta a distribuição de tamanho de partícula do chamote. O chamote apresenta uma curva de tamanho de partícula relativamente bem distribuída com D50 de 160,1 $\mu \mathrm{m}$. A argila é predominantemente caulinítica, apresentando baixo percentual de óxidos fundentes $\left(\mathrm{K}_{2} \mathrm{O}+\mathrm{Na}_{2} \mathrm{O}\right), 2,42 \%$, teor relativamente elevado de alumina, $25,16 \%$, e perda ao fogo de $10,20 \%$ [8].

Foram preparadas quatro composições: uma de argila pura (A) e três com adição de chamote de 5 (A5C), 10 (A10C) e $20 \%$ em peso (A20C). As composições foram homogeneizadas

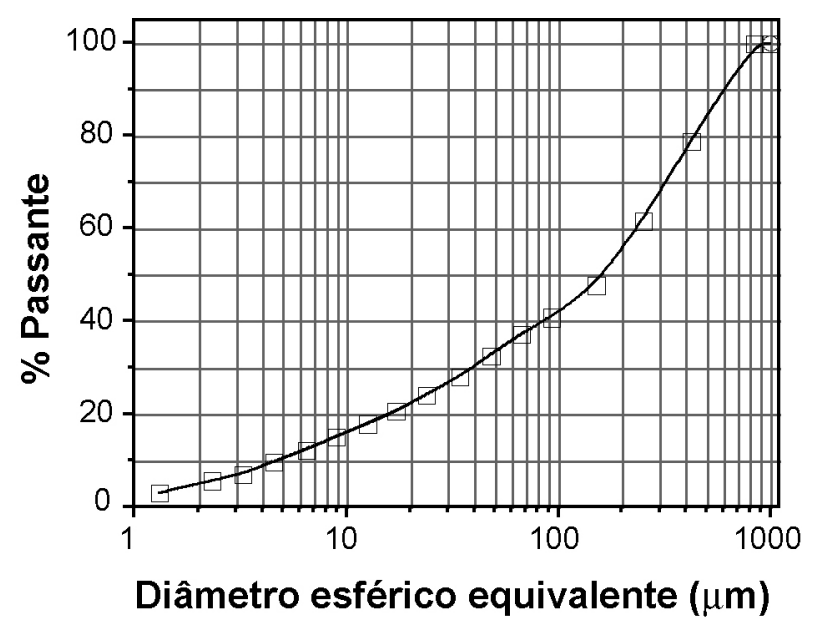

Figura 1: Distribuição de tamanho de partícula do chamote. [Figure 1: Particle size distribution of the grog.] a seco em galga misturadora de pista lisa da Gardelin.

Corpos-de-prova cilíndricos com diâmetro de $31 \mathrm{~mm}$ e altura de $11 \mathrm{~mm}$ foram prensados uniaxialmente a $20 \mathrm{MPa}$ com $8 \%$ de água. Em seguida, os corpos-de-prova foram secos a $110{ }^{\circ} \mathrm{C}$ em estufa até peso constante. A queima foi realizada em forno elétrico de laboratório em temperaturas de $500{ }^{\circ} \mathrm{C}$ a $1100{ }^{\circ} \mathrm{C}$, com 60 min de patamar. A taxa de aquecimento foi 3 ${ }^{\circ} \mathrm{C} / \mathrm{min}$. O resfriamento foi realizado desligando-se o forno. As propriedades determinadas foram densidade aparente, retração diametral de queima, absorção de água e resistência mecânica. A densidade aparente dos corpos-de-prova, tanto secos quanto queimados, foi determinada pelo método dimensional. A retração diametral de queima foi determinada com paquímetro. A absorção de água foi calculada determinando-se a massa de água absorvida pelos corpos-de-prova queimados após terem sido imersos em água fervente por $2 \mathrm{~h}$. A resistência mecânica foi avaliada por meio da determinação da compressão diametral [10] em máquina universal de ensaios Instron 5582.

A análise dos vazios microestruturais foi feita com ensaios de porosimetria de mercúrio em porosímetro Quantachrome Autoscan 33, com ângulo de contato de $140^{\circ}$. A observação da região de fratura de corpos de prova rompidos em compressão foi feita por microscopia eletrônica de varredura em um microscópio Zeiss DSM 962.

\section{RESULTADOS E DISCUSSÃO}

A Tabela I mostra a densidade aparente a seco das composições. A adição de chamote diminuiu ligeiramente a densidade aparente a seco da argila. Este resultado indica que a argila tem, provavelmente, uma adequada relação entre partículas finas e grosseiras. A adição de chamote com partículas mais grosseiras prejudicou o empacotamento da argila [11].

Tabela I - Densidade aparente a seco $\rho_{\mathrm{s}}$ das composições. [Table I - Dry bulk density $\rho_{s}$ of the compositions.]

\begin{tabular}{ccccc}
\hline & A & A5C & A10C & A20C \\
\hline$\rho_{\mathrm{s}}$ & 1,97 & 1,95 & 1,92 & 1,92 \\
$\left(\mathrm{~g} / \mathrm{cm}^{3}\right)$ & $\pm 0,01$ & $\pm 0,01$ & $\pm 0,01$ & $\pm 0,01$ \\
\hline
\end{tabular}

A Fig. 2 apresenta a absorção de água das composições em função da temperatura de queima. Dentro do erro estatístico, a absorção de água das composições apresentou pequeno aumento de 500 a $900{ }^{\circ} \mathrm{C}$. A $1100{ }^{\circ} \mathrm{C}$ a absorção de água diminuiu abruptamente, o que está associado com o processo de vitrificação [12]. Embora a argila apresente baixo teor de óxidos fundentes, a partir de $1050{ }^{\circ} \mathrm{C}$ as argilas de cauliníticas de Campos dos Goytacazes apresentam uma brusca redução da porosidade [13]. Observa-se também que, para cada temperatura investigada, a adição de chamote pouco afetou a absorção de água em relação à argila pura.

A Fig. 3 apresenta a retração diametral em função da temperatura de queima. É possível observar que, para todas 


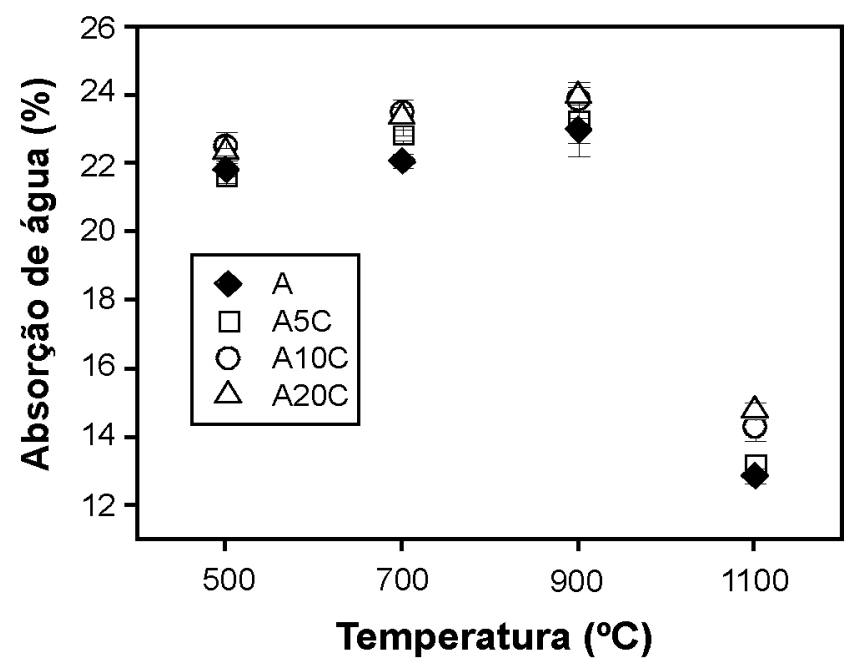

Figura 2: Absorção de água das composições em função da temperatura de queima.

[Figure 2: Water absorption of the compositions as a function the firing temperature.]

as composições ocorreu um pequeno aumento da retração de 500 a $900{ }^{\circ} \mathrm{C}$. A partir daí, a retração aumentou bruscamente. Este comportamento é também atribuído ao processo de vitrificação que possibilita a redução da porosidade promovendo a aproximação das partículas. A incorporação de chamote em até $20 \%$ praticamente não causa variação da retração da argila de 500 a $900{ }^{\circ} \mathrm{C}$. Já a $1100{ }^{\circ} \mathrm{C}$ é possível observar que a composição A20C apresenta retração um pouco menor em comparação com as demais composições investigadas. Isto ocorreu possivelmente devido à sua granulometria mais grosseira, em comparação com a argila, que dificultou sua sinterização por fase líquida.

A Fig. 4 apresenta a compressão diametral das composições em função da temperatura de queima. Observa-

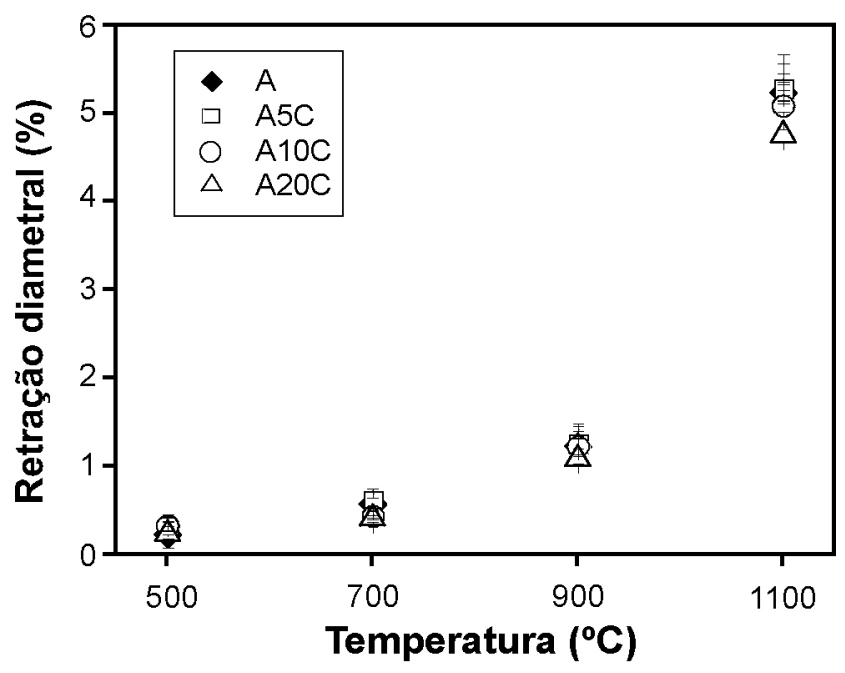

Figura 3: Retração diametral das composições em função da temperatura de queima.

[Figure 3: Diametral shrinkage of the compositions as a function the firing temperature.] se que não ocorrem diferenças significativas na compressão diametral das composições estudadas de 500 a $900{ }^{\circ} \mathrm{C}$. A partir daí, ocorre um brusco incremento desta propriedade devido à redução da porosidade pelo efeito dos processos de sinterização, sobretudo, pela formação de fase líquida vitrificação. É também importante observar que as adições de chamote acima de 5\% reduziram a resistência mecânica da cerâmica. Isto pode ser atribuído à porosidade interna, porosidade intragranular e aglomerados de chamote que agem como grandes defeitos em combinação com a maior porosidade intergranular das composições A10C e A20C. Além disso, conforme já mencionado, a granulometria mais grosseira do chamote prejudicou a sinterização das partículas em comparação com a argila.

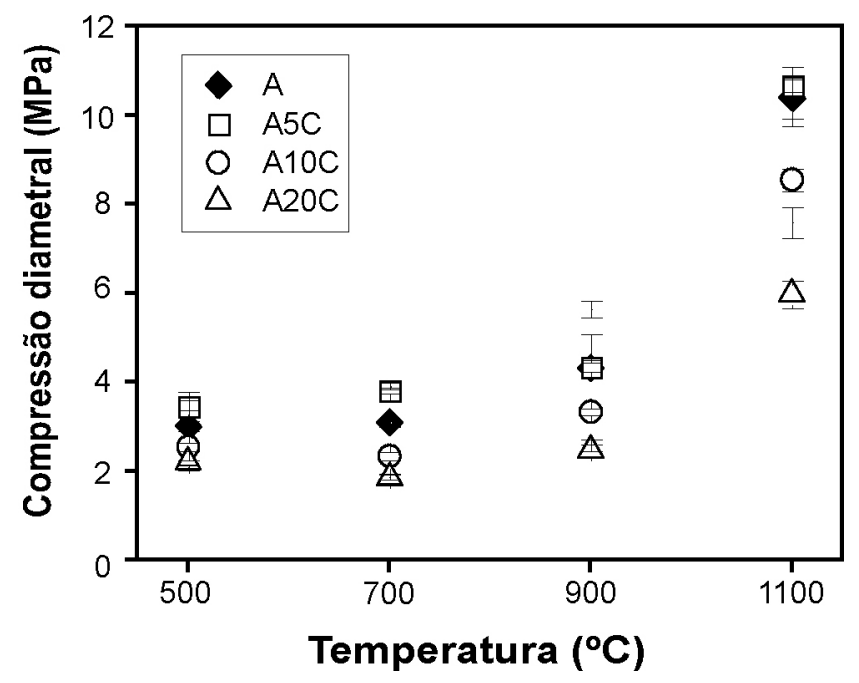

Figura 4: Compressão diametral das composições em função da temperatura de queima.

[Figure 4: Diametral compression of the compositions as a function the firing temperature.]

As Figs. 5 e 6 apresentam a região de fratura das composições A e A20C queimadas a 700 e $1100{ }^{\circ} \mathrm{C}$, respectivamente. Ambas as composições apresentaram, a $700{ }^{\circ} \mathrm{C}$, uma região de fratura com morfologia grosseira associada a partículas rugosas e com poucas áreas lisas. É possível também observar que nesta temperatura já ocorreu consolidação das partículas ainda que predominasse uma microestrutura porosa com interconectividade de poros. Por outro lado, na temperatura de $1100{ }^{\circ} \mathrm{C}$ todas as composições apresentaram uma região de fratura mais consolidada com predominância de áreas lisas típicas de vitrificação.

A Fig. 7 apresenta as curvas de distribuição de tamanho de poros para as composições A e A20C. É possível observar que o incremento da temperatura de queima exerceu uma influência significativa na porosidade das composições investigadas. $\mathrm{Na}$ temperatura de $1100{ }^{\circ} \mathrm{C}$, tanto a argila pura A quanto a composição com $20 \%$ de chamote A20C apresentaram menor porosidade aberta em comparação com amostras queimadas a $700{ }^{\circ} \mathrm{C}$. Entretanto, ocorreu um 

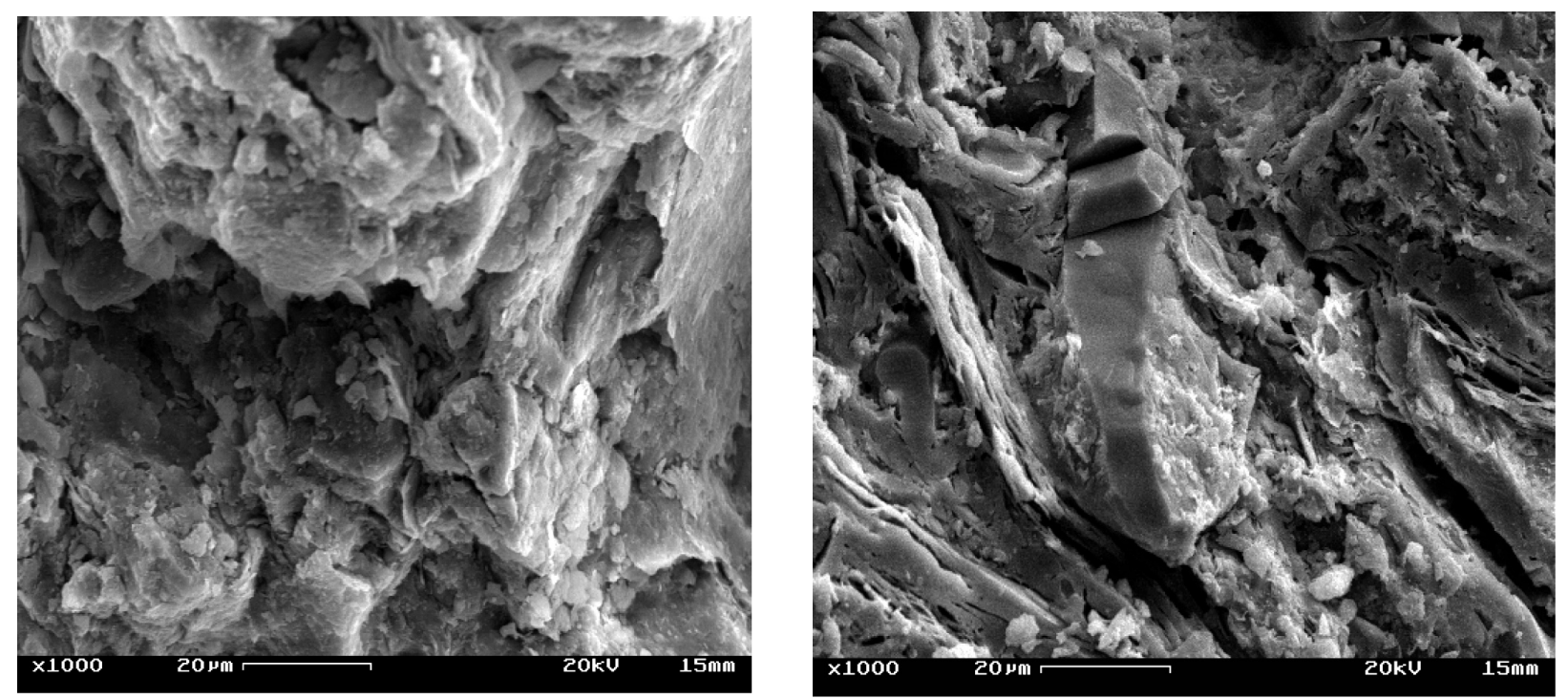

Figura 5: Micrografias obtidas por MEV da região de fratura da composição A. (a) $700{ }^{\circ} \mathrm{C}$. (b) $1100{ }^{\circ} \mathrm{C}$. [Figure 5: SEM micrographs of the fracture region of the composition A. (a) $700^{\circ} \mathrm{C}$. (b) $1100^{\circ} \mathrm{C}$.]
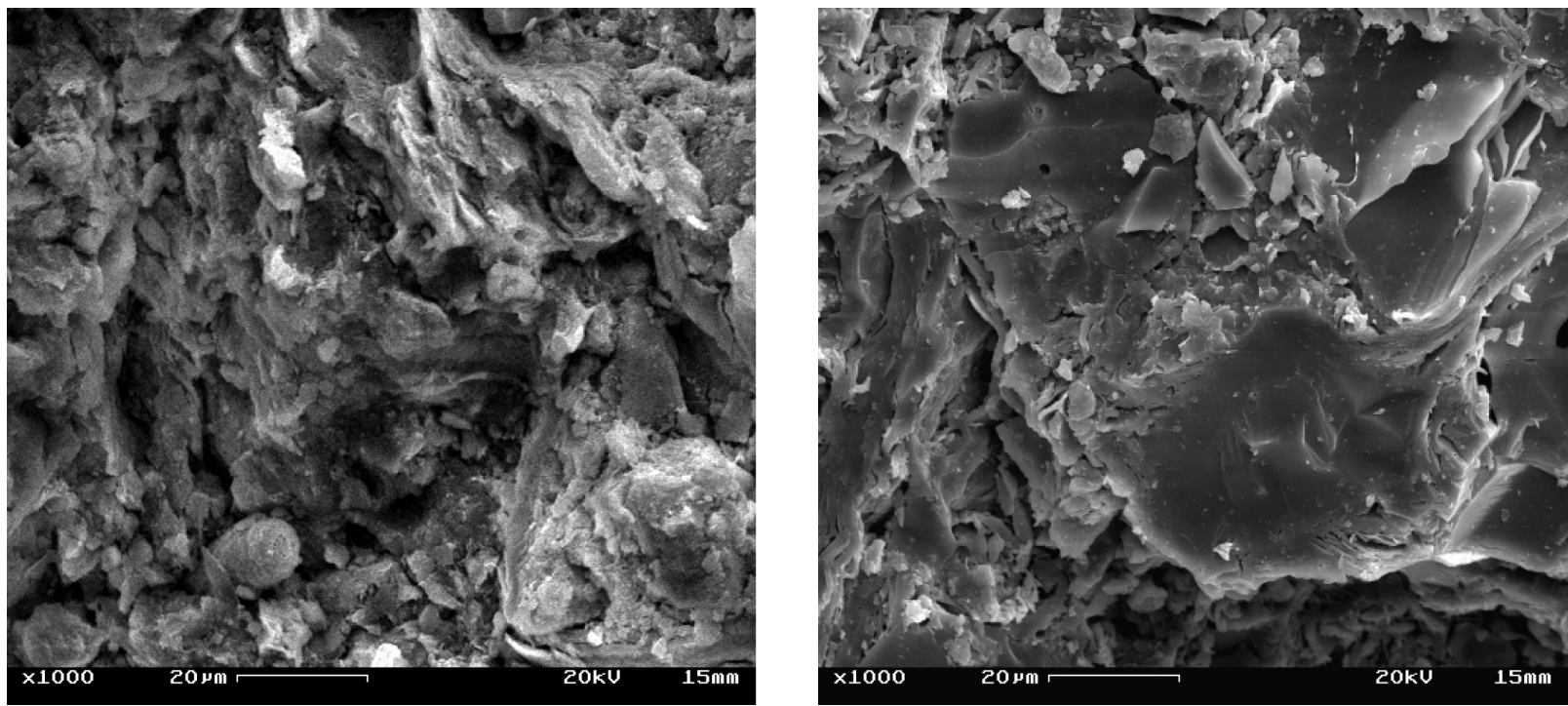

Figura 6: Micrografias obtidas por MEV da região de fratura da composição A20C. (a) $700{ }^{\circ} \mathrm{C}$. (b) $1100{ }^{\circ} \mathrm{C}$. [Figure 6: SEM micrographs of the fracture region of the composition $\mathrm{A20C}$. (a) $700{ }^{\circ} \mathrm{C}$. (b) $1100^{\circ} \mathrm{C}$.]

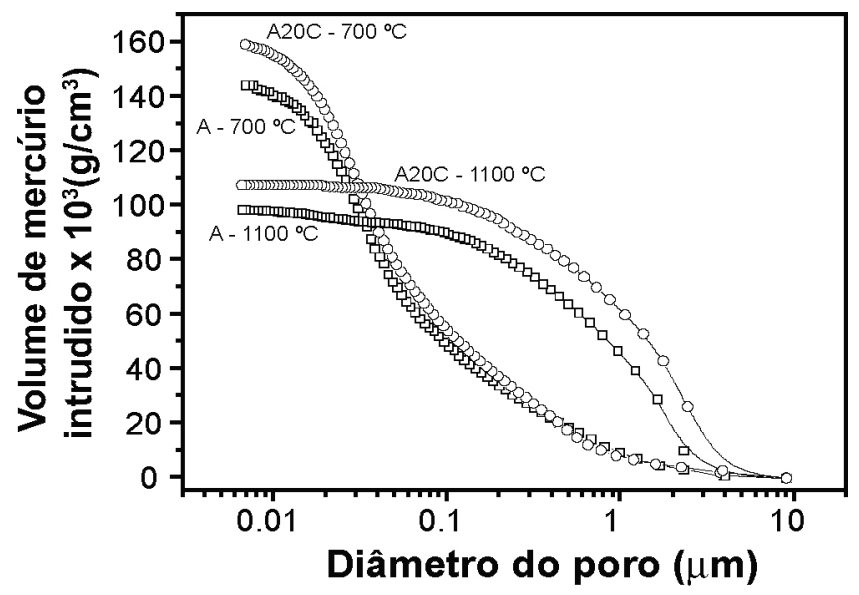

Figura 7: Curvas de distribuição de tamanho de poros das composições A e A20C queimadas a 700 e $1100{ }^{\circ} \mathrm{C}$. [Figure 7: Pore size distribution curves of the compositions A and A20C fired at 700 e $1100^{\circ} \mathrm{C}$.] 
incremento no tamanho de poros. Isto pode ser atribuído ao fechamento preferencial dos poros pequenos durante os estágios intermediários de sinterização, o que acarreta aumento dos poros inicialmente com maior tamanho [14]. A Fig. 7 mostra também que tanto a $700{ }^{\circ} \mathrm{C}$ quanto a $1100{ }^{\circ} \mathrm{C}$ a adição de $20 \%$ em peso de chamote contribuiu para o incremento da porosidade aberta da argila. Estes resultados estão de acordo com o comportamento das propriedades dependentes da porosidade do material, ou seja, absorção de água e resistência mecânica.

\section{CONCLUSÕES}

A adição de chamote reduziu discretamente a densidade aparente a seco da massa cerâmica em consequiência das respectivas distribuições de tamanhos de partículas que acarretaram dificuldade de empacotamento.

Nas propriedades de queima avaliadas foi observado que de 500 a $900{ }^{\circ} \mathrm{C}$ praticamente não houve variação significativa nos valores de compressão diametral das composições. Já a absorção de água e a retração sofreram pequeno aumento nesta faixa de temperatura. A $1100{ }^{\circ} \mathrm{C}$ ocorreu um brusco aumento da retração e da compressão diametral e redução da absorção de água das composições em função do processo de vitrificação.

A incorporação de chamote praticamente não alterou a absorção de água e a retração da argila em todas as temperaturas investigadas. Incorporações de chamote acima de 5\% são prejudiciais à resistência mecânica da argila.

\section{AGRADECIMENTOS}

Ao CNPq (Proc. 150444/2003-6) pelo financiamento desta pesquisa, à UENF, e ao TECNORTE/FENORTE e FAPERJ pela concessão de bolsas de iniciação científica e de apoio técnico.

\section{REFERÊNCIAS}

[1] S. Pracidelli, F. G. Melchiades, Cerâmica Industrial 2, 1-2 (1997) 31.

[2] F. Ripoli Filho, Cerâmica 43, 281-282 (1997) 281.

[3] J. Vicenzi, D. L. Villanova, T. P. Madruga, C. P. Bergmann, Anais $55^{\circ}$ Cong. Anual ABM, Rio de Janeiro, RJ (2000) cdrom, pp. 1579-1588.

[4] D. L. Villanova, J. Vicenzi, T. P. Madruga, C. P. Bergmann, Anais $55^{\circ}$ Cong. ABM, Rio de Janeiro, RJ (2000) cdrom, pp.1569-1578.

[5] Manfredini \& Schianchi do Brasil Ltda, Cerâmica Industrial 7, 6 (2002) 34.

[6] V. Beltrán, E. Ferrando, J. García y E. Sánchez, Tile \& Brick Int. 11, 3 (1995) 169.

[7] E. T. A. de Souza, S. N. Monteiro,C. M. F. Vieira, Anais do XVI Cong. Bras. Eng. Ci. Mater., Porto Alegre, RS (2004) cdrom.

[8] C. M. F. Vieira, E. T. A. de Souza, S. N. Monteiro, Industrial Ceramics 24, 2 (2004) 85.

[9] C. M. F. Vieira, E. T. A. de Souza, S. N. Monteiro, Cerâmica 50, 315 (2004) 254.

[10] S. J. Schneider Jr., Engineered Materials Handbook Ceramics and Glasses, Ed. ASM International, EUA (2000) p. 589 .

[11] L. H. Van Vlack, Propriedades dos Materiais Cerâmicos, Ed. Universidade de S. Paulo, SP (1973) p. 246.

[12] W. D. Kingery, H. K. Bowen, D. R. Uhlmann, Introduction to Ceramics, Ed. Wiley Interscience Publ., New York, EUA (1976) p. 1032.

[13] S. N. Monteiro, C. M. F. Vieira, Applied Clay Sci. 27 (2004) 229.

[14] M. J. Ortz, A. Escardino, J. L. Amorós, F. Negre, Appl. Clay Sci. 8 (1993) 193.

(Rec. 05/08/2008, Ac. 17/04/2009) 